\title{
Peertechz
}

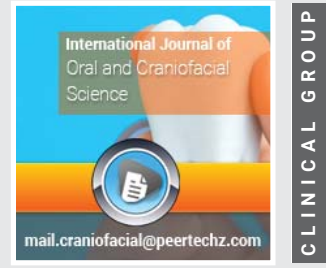

\section{An unusual case of large epidermoid inclusion cystic lesion in the floor of the \\ mouth causing double chin}

\section{appearance}

\section{Satnam Singh*}

Assistant Professor, Unit of Oral and Maxillofacial Surgery, Post Graduate Institute of Medical

Education and Research (PGIMER) Chandigarh, Chandigarh, India

Received: 13 Jaunary, 2020

Accepted: 06 November, 2020

Published: 07 November, 2020

*Corresponding author: Satnam Singh, Assistant Professor, Unit of Oral and Maxillofacial Surgery, Post Graduate Institute of Medical Education and Research (PGIMER) Chandigarh, Chandigarh, India, Tel: 9914287909; 01722756847;

E-mail: SATNAMSURGEON@GMAIL.COM

Keywords: Swelling; Floor of mouth; Tumour; Enucleation; Epidermoid cyst

https://www.peertechz.com

\section{Check for updates}

\section{Introduction}

Epidermal inclusion cyst is painless, rare slow-growing swelling in midline due to the inclusion of ectodermal tissue into unusual sites. These cysts are covered under the teratomas category due to the absence of skin appendages within their squamous epithelium-lined thin walls. Testes and ovaries are the common sites of occurrence of epidermal cysts [1]. In the head and neck region these are mostly seen in the lateral third of the eyebrows. Epidermoid cysts comprise less than $0.01 \%$ of all intraoral cysts and are even less frequently seen as compared to dermoid cysts of the oral cavity [1,2]. Frequently, reported in infancy but in adults can be seen in third to fifth decades of the life. Clinically these can be classified depending upon their location as supramylohyoid and inframylohyoid in relation to the mylohyoid muscle, or medial and lateral to the midline of the neck $[3,4]$. These generally do not cause discomfort, but with an increase in size and elevation of the tongue, it can cause dysphasia, dyspnoea, and a double chin" if left untreated $[4,5]$. This article describes a 51-year-old male patient with swelling in the floor of the mouth and submental region with double chin appearance treated by an extraoral approach under general anaesthesia.

\section{Case report}

A 51-year-old male patient came to our unit with a painless swelling on the floor of the mouth on left side from 3-4 months. Extraoral, a small plunging bump in the submental region was present, which did not disappear on protrusion of the tongue.
The swelling was soft and nodular, giving a double chin appearance. On Intraoral examination, a pinkish white bulge of $3 \times 3 \mathrm{~cm}$ in the left sublingual region protruding upward raising the floor of the mouth was noted. On palpation, it was soft, spongy, cystic in nature, compressible with palpable margins, and mobile on bimanual palpation. Tongue movements were normal on the right side and slightly reduced on the left side. No carious tooth and cervical lymph-adenopathy were present. Computed tomographic (CT) imaging showed a large 3 $44 \mathrm{~cm}$ hypodense, non-enhancing cystic lesion in the floor of the mouth, and submental region without lymphadenopathy. Excision of the lesion was done extra-orally under general anaesthesia through a transverse incision in the submental area, and a lesion of 3x $4 \mathrm{~cm}$ soft-lined dumbbell-shaped was separated from surrounding tissue by blunt dissection and removed in toto. The histopathological features of the specimen showed a cyst lined by stratified squamous epithelium with granular layer and keratin flakes. The sub epithelium showed mild lymphomononuclear infiltrates and few congested capillaries, concluding epidermal inclusion cyst. Postoperative recovery was uneventful up to six months of follow-up without any complications and recurrence Figures 1,2.

\section{Discussion}

Epidermoid cysts are rarely seen compared to dermoid cysts in the head and neck region and are unusual and represent less than $0.01 \%$ of all oral cavity cysts [1]. Mayo Clinic,s study by Erich and New found only $1.6 \%$ of cases of dermoid cysts in the oral cavity in their 1459 pathology cases $[3,4]$. These are 

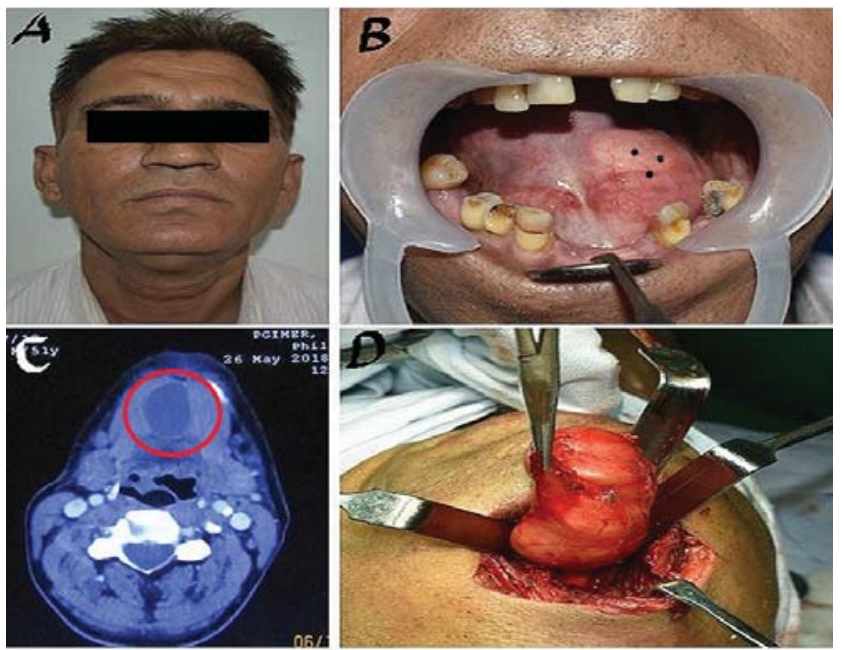

Figure 1: Extraoral swelling in submental region Figure 1B: intraoral picture showing swelling in the floor of mouth left side. Figure 1C: CT floor of the mouth showing a well defined hypodense radiolucent lesion Figure 1D: Extraoral removal of the whole lesion in totto.
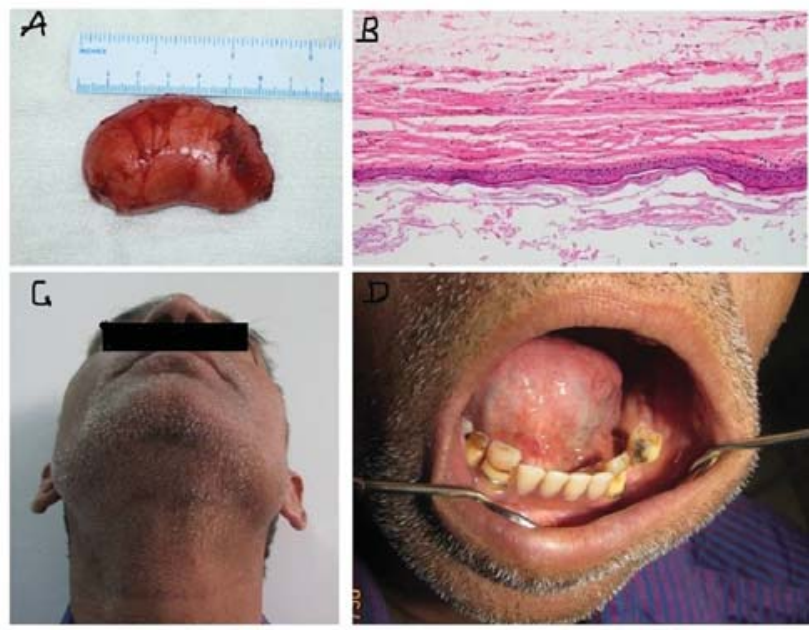

Figure 2: $\mathrm{A}$ in totto removed lesion. $2 \mathrm{~B}$ Histological picture $10 \mathrm{X}$ magnification showing a cyst lined by stratified squamous epithelium with granular layer and keratin flakes. 2C Post-surgery extraoral image with no swelling. 2D Intraoral view after surgery depicting normal floor of mouth left side.

benign squamosal epithelial lined masses, usually filled with pultaceous cheesy material. The most typical site of epidermoid cysts is in the testes and ovaries, rarely found in the oral cavity, and the usual location is the floor of the mouth $[4,5]$. There is no sex predilection and is mostly seen in the third to fifth decade of life. According to Meyer's classification, the dermoid cysts are differentiating into three categories, i.e., dermoid, epidermoid, and teratoid. Dermoid cysts have adnexal tissue in the wall along with squamous epithelium. The epidermoid cyst is the primary type lined by squamous epithelium and the fibrous wall. At the same time, teratoid variety may have tissues from primary germ layers I,e ectoderm, mesoderm, and endoderm [5]. The sebaceous cyst is often misinterpreted with an epidermoid cyst. The study of the content of these cysts concerning lipid pattern and cytokeratins helps differentiate between them [6]. The etiology related to epidermal cysts considered be due to ectodermal tissue entrapment during the development of first and second branchial arches at the time of their fusion. Other theories like thyroglossal duct remnants, human papillomavirus infection, and occlusions like pilosebaceous or eccrine duct are also discussed in the literature by various authors [7].

Clinically these cysts reported are nonpainful, slow-growing swelling in the floor of the mouth, sublingual, submandibular, and submental region [8]. These swelling are fluctuant, without pulsations, and raised the floor of the oral cavity when presents above the mylohyoid muscle. These can also cause dysphasia, dyspnoea, and double chin when increased in size.

Diagnosis is usually made by clinical examination, aspiration, ultrasound, CT, and magnetic resonance imaging to see the extent of the lesion and type of lining. Fine needle aspiration cytology also provides an important clue regarding the content of cysts and cells present in the cavity [3,5]. The final diagnosis is always based on the histopathological examination of the entire lesion.

Management depends upon the size and location of the cystic lesion. An intraoral approach is conserved for small and supramylohyoid variety cysts [2]. The extraoral submental approach is used for large and deep inframylohyoid lesions, adhered to underlying vital structures. In toto removal of the lesion without rupture or spillage decreased the risks of recurrence.

\section{References}

1. King RC, Smith BR, Burk JL (1994) Dermoid cyst in the floor of the mouth: Review of the literature and case reports. Oral Surg, Oral Med, Oral Pathol 78: 567-576. Link: https://bit.ly/2TYHsTd

2. Di Fransesco A, Chiapasco M, Biglioli F, Ancona D (1995) Intraoral approach to large dermoid cysts of the floor of the mouth: A technical note. Int J Oral Maxillofac Surg 24: 233-235. Link: https://bit.ly/354V0mG

3. Walstad WR, Solomon JM, Schow SR, Ochs MW (1998) Midline cystic lesion of the floor of the mouth. J Oral Maxillofacial Surg 56: 70-74. Link: https://bit.ly/3eujRmZ

4. Louis PJ, Hudson C, Reddi S (2002) Lesion of the floor of the mouth. J Oral Maxillofac Surg 60: 804-807. Link: https://bit.ly/2TXkBY2

5. Longo F, Maremonti P, Mangone GM, De Maria G, Califano L (2003) Midline (dermoid) cysts of the floor of the mouth: report of 16 cases and review of surgical techniques. Plast Reconstr Surg 112: 1560-1565. Link: https://bit.ly/2TZhxLc

6. Patil K, Mahima VG, Malleshi SN (2009) Sublingual epidermoid cyst: a case report. Cases J 2: 8848. Link: https://bit.ly/36cTpKy

7. Dutta M, Saha J, Biswas J, Sen I, Sinha R (2013) Epidermoid Cysts in Head and Neck: Our Experiences, with review of Literature. Indian J Otolaryngol Head Neck Surg 65: 14-21. Link: https://bit.ly/352TaCD

8. Salaria N, Garg U, Singla A (2017) Giant epidermal inclusion cyst: an unusual case presentation. Int J Otorhinolaryngol Head Neck Surg 3: 166-169. Link: https://bit.ly/32ljRAJ 